\title{
Efficacy and Acceptance of a Lombard-response Device for Hypophonia in Parkinson's Disease
}

\author{
Scott Adams (1D, Niraj Kumar, Philippe Rizek, Angeline Hong, Jenny Zhang, \\ Anita Senthinathan, Cynthia Mancinelli, Thea Knowles, Mandar Jog (iD
}

\begin{abstract}
Objective: The purpose of this study was to examine the effectiveness, satisfaction, and acceptance of a low-cost Lombard-response (LR) device in a group of individuals with Parkinson's disease (IWPD) and their communication partners (CPs). Method: Sixteen IWPD and hypophonia and their CPs participated in the study. The IWPD wore a LR device that included a small MP3 player (Sony Walkman) and headphones playing a multi-talker noise audio file at $80 \mathrm{~dB}$ during lab-based speech tasks and during their daily conversational speech over a 2 -week device trial period. Outcome measures included average conversational speech intensity and scores on a questionnaire related to speech impairment, communication effectiveness, and device satisfaction. Results: Conversational speech intensity of the IWPD is increased by 7 to $10 \mathrm{~dB}$ with the LR device. Following a 2-week trial period, eight of the IWPD (50\%) gave the LR device moderate-to-high satisfaction and effectiveness ratings and decided to purchase the device for long-term daily use. At the 4-month follow-up, none of the IWPDs were still using the LR device. Device rejection was related to discomfort (loudness), headaches, interference with cognition, and difficulty controlling device. Conclusion: Short-term acceptance and satisfaction with the LR device was moderate, but long-term acceptance, beyond 4 months, was absent. Future studies are required to determine if other types of low-cost LR devices can be developed that improve long-term efficacy and device acceptance in IWPD and hypophonia.
\end{abstract}

RÉSUMÉ : Efficacité et acceptation d'un dispositif mesurant l'effet Lombard dans le cas d'individus atteints d'hypophonie en lien avec la maladie de Parkinson. Objectif : Cette étude a pour objectif d'examiner à la fois l'efficacité, la satisfaction et l'acceptation d'un dispositif bon marché mesurant l'effet Lombard dans le cas d'un groupe d'individus atteints de la maladie de Parkinson (MP) et de leurs interlocuteurs. Méthode : Au total, 16 individus atteints de MP et d'hypophonie, de même que leurs interlocuteurs, ont participé à cette étude. Ces 16 individus étaient munis d'un dispositif mesurant l'effet Lombard, ce qui incluait un petit lecteur MP3 (Sony Walkman ${ }^{\circledast}$ ) et un casque d'écoute. À partir d'un fichier audio, ce dispositif devait ainsi diffuser un bruit de fond de $80 \mathrm{~dB}$ produit par plusieurs locuteurs, et ce, pendant que ces 16 individus accomplissaient en laboratoire des taches langagières mais aussi des taches langagières quotidiennes au cours d'une période de deux semaines. Les résultats mesurés ont inclus l'intensité moyenne du langage au cours de conversations ainsi que des scores à un questionnaire portant sur les troubles de la parole, l'efficacité de la communication et la satisfaction liée au dispositif lui-même. Résultats : Pour ces 16 individus, l'intensité de leur langage en cours de conversation a augmenté de 7 à $10 \mathrm{~dB}$ avec leur dispositif. Après leur période d'utilisation de deux semaines, 8 d'entre eux (50 \%) ont donné à un tel dispositif des scores de satisfaction et d'efficacité allant de modérés à élevés et ont décidé de l'acquérir en vue d'une utilisation quotidienne à long terme. Cela dit, lors d'un suivi au bout de quatre mois, plus personne n'utilisait encore le dispositif. Son rejet était lié à l'inconfort produit (à savoir le volume sonore), à des maux de tête, à une interférence avec la cognition et à des difficultés à le maîtriser. Conclusion : L'acceptation et la satisfaction à court terme d'un tel dispositif mesurant l'effet Lombard se sont avérées modérées ; à long terme, au-delà de quatre mois, l'acceptation apparaît inexistante. De futures études sont ainsi nécessaires afin de déterminer si d'autres types de dispositifs bon marché mesurant l'effet Lombard peuvent être développés dans le but d'améliorer leur efficacité et leur acceptation à long terme dans le cas de patients atteints de MP et d'hypophonie.

Keywords: Parkinson's disease, Hypophonia, Lombard effect, Speech intensity, Communication device doi:10.1017/cjn.2020.90

Can J Neurol Sci. 2020; 47: 634-641

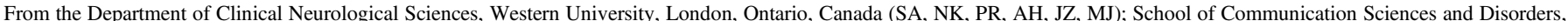

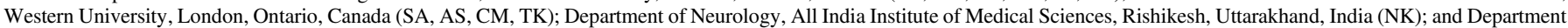
of Speech-Language Pathology, State University of New York (SUNY), Buffalo State, Buffalo, NY, USA (AS)

Received November 10, 2019. Final Revisions Submitted April 30, 2020. Date of Acceptance May 2, 2020.

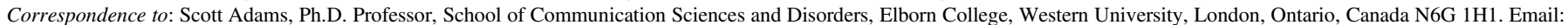
sadams@uwo.ca 
Table 1: Examples of four Lombard-response devices

\begin{tabular}{l}
\hline 1. Edinburgh masker (http://www.mnsu.edu/comdis/kuster/edinburghmasker.html) \\
\hline 2. Kay Elemetrics Facilitator (http://archive.li/8mESS) \\
\hline 3. iParkinson smartphone app (http://www.casafuturatech.com/iparkinsons/) \\
\hline 4. SpeechVive (http://www.speechvive.com/) \\
\hline
\end{tabular}

\section{INTRODUCTION}

Parkinson's disease (PD) is a neurodegenerative disease characterized by damage to specific basal ganglia subsystems and their associated sensorimotor processes. ${ }^{1}$ PD is the second most common neurodegenerative disease with an estimated prevalence of between 1 and 3 per 100 people of 65 years and older, $^{2}$ and approximately $70 \%$ of individuals with PD will develop speech impairments. ${ }^{3}$ One of the most prevalent and distinctive speech symptoms in idiopathic PD is hypophonia (reduced speech intensity). Hypophonia typically decreases speech intelligibility and hinders oral communication in a multitude of social contexts. ${ }^{4}$ Behavioral treatments for hypophonia can be effective in PD, but some individuals fail to retain and transfer improvements in speech intensity beyond the context of the clinical setting. These transfer difficulties may be related to perceptual, cognitive, and sensorimotor deficits associated with PD that inhibit the incorporation of new speech strategies into habitual speech. ${ }^{4}$ Assistive devices for hypophonia may provide a solution to the transfer of treatment problem for some individuals with PD. The presentation of masking noise or multi-talker background noise has been shown to produce a significant increase in speech intensity in healthy participants and in individuals with hypophonia related to $\mathrm{PD} .^{5-8}$ It has been proposed that this response, known as the Lombard response (LR), ${ }^{9,10}$ could be incorporated into assistive devices for PD..$^{5}$ A few LR devices have been developed for hypophonia and other speech deficits (see Table 1). These LR devices can show considerable variation in their physical dimensions (i.e. size of a hearing aid vs. size of smartphone), features (i.e. voice activation vs. manual activation; monaural vs. binaural; multi-talker noise (MTN) vs. nonspeech noise), and cost (i.e. \$99 vs. \$2600). Unfortunately, there is limited information on the long-term effectiveness, satisfaction, and acceptance of these LR devices by individuals with PD and their communication partners (CPs). ${ }^{11,12}$

The purpose of the present study was to examine the long-term effectiveness, satisfaction, and acceptance of a low-cost LR device in a group of individuals with hypophonia related to PD and their CPs.

\section{Methods \\ Participants}

Sixteen individuals with PD (IWPD) and hypophonia (14 males) and 16 CPs (i.e. spouse) served as participants. Hypophonia was the primary speech symptom in all PD participants. This was determined during a clinical speech assessment by one experienced Speech-Language Pathologist (SLP). To classify hypophonia severity, a simple clinical judgment of mild-moderate or severe hypophonia was made by one experienced SLP (SA) during the initial study visit, while the patient produced conversational speech in a quiet room at a listener-totalker distance of $2 \mathrm{~m}$. In addition, the speech score from the Unified Parkinson Disease Rating Scale: section III (UPDRS-III) was obtained for each participant by a movement disorder specialist (neurologist) during the initial study visit. Table 2 provides demographic and descriptive information for each PD participant for the following: age, sex, PD duration (years), years of deep brain stimulation (DBS years), UPDRS-III score (x/108), UPDRS-III speech score ( $\mathrm{x} / 4)$, severity of hypophonia (mild-moderate, severe), Hoehn and Yahr (H-Y) stage, levodopa equivalent dose (LED), and Montreal Cognitive Assessment (MOCA) score (x/30). The IWPD had the following characteristics (see Table 2): average age of 67.7 years (range 52-80 years), average PD duration of 13.7 years (range $3-23$ ), average UPDRS-III score of 24.7/108 (range 12-40), average UPDRS-III speech score of 2.5 (range 2-3), average $\mathrm{H}-\mathrm{Y}$ stage of 2.8 (range 2-4), average LED of $799.7 \mathrm{mg}$ (range 0-1800 mg), and an average MOCA score of 21.6/30 (range 11-29; seven $<21$ ). In addition, seven participants had mild-moderate hypophonia and nine participants had severe hypophonia. Nine of the IWPD had received bilateral subthalamic nucleus deep brain stimulation (STN-DBS) within the previous 1-6 years. It is noted in Table 2 that five of the nine participants with DBS had a worsening of hypophonia following DBS surgery. All nine participants with DBS had been optimized for their PD symptoms (including hypophonia/dysarthria) at least 6 months prior to the study, and none of the DBS parameters were adjusted during the current study. A preliminary analysis (t-tests) found no significant difference between participants with and without STN-DBS for any of the dependent measures. Thus, the data were collapsed across these IWPDs. None of the IWPD were cigarette smokers. All IWPD and CP participants, except one, passed a 40-dB hearing screening at $0.5,1$, and $2 \mathrm{kHz}$ (one IWPD had $45 \mathrm{~dB}$ at $2 \mathrm{kHz}$ ). All PD participants who were receiving regular levodopa were tested in an "on" levodopa medication state.

\section{Device}

A small $(4 \times 11 \mathrm{~cm})$ MP3 player (Sony Walkman (NWZB183FB); \$50) connected to a set of over-the-ear headphones (JVC Flats (HAS160BN); \$20) running a continuously repeating audio file containing MTN, composed of a blend of four talkers played at a volume setting of 80 or $90 \mathrm{dBA}$ SPL, was used as the LR device in the present study.

\section{Procedures}

The IWPD read aloud eight sentences and had a 2-minute conversation during four conditions that included (1) no device, (2) LR device playing MTN at $80 \mathrm{dBA}$ via bilateral headphones, (3) LR device playing MTN at $90 \mathrm{dBA}$ via bilateral headphones, and (4) LR device playing MTN at $80 \mathrm{dBA}$ via mono-lateral (left) headphone. The IWPD repeated these procedures at the initial visit and at a 2 -week visit. During the 2 -week interval, participants used the LR device every day for at least 2 hours. The IWPD were requested to use the bilateral $80 \mathrm{~dB}$ MTN condition throughout the 2-week trial period. Speech conditions were audio-recorded with a calibrated microphone placed $60 \mathrm{~cm}$ in front of the participant. Average conversational speech intensity was obtained for each of the four conditions using Praat software. ${ }^{13}$ Three visual analog rating scale type questions were 
Table 2: PD participant demographic and descriptive information related to age, sex, PD duration, years of DBS, UPDRS score (x/108), UPDRS speech score (x/4), severity of hypophonia (mild-moderate, severe), Hoehn and Yahr (H-Y) stage, Levodopa equivalent dose (LED), and Montreal Cognitive Assessment (MOCA) score (x/30)

\begin{tabular}{|c|c|c|c|c|c|c|c|c|c|c|c|}
\hline PD & Age & Sex & $\begin{array}{c}\text { PD } \\
\text { duration } \\
\text { (years) }\end{array}$ & $\begin{array}{c}\text { DBS } \\
\text { duration } \\
\text { (years) }\end{array}$ & $\begin{array}{c}\text { Worsening } \\
\text { of hypo. } \\
\text { after DBS }\end{array}$ & $\begin{array}{c}\text { UPDRS } \\
\text { score }(\mathbf{1 0 8})\end{array}$ & $\begin{array}{c}\text { UPDRS } \\
\text { speech } \\
\text { score (4) }\end{array}$ & $\begin{array}{l}\text { Severity of } \\
\text { hypophonia }\end{array}$ & H-Y stage & LED & MOCA (30) \\
\hline $1^{*}$ & 69 & M & 20 & 6 & No & 29 & 3 & Severe & 3 & 1100 & 19 \\
\hline $2^{*}$ & 65 & M & 18 & 6 & No & 12 & 3 & Severe & 2 & 600 & 18 \\
\hline $3^{*}$ & 77 & $\mathrm{~F}$ & 16 & 4 & No & 12 & 2 & Severe & 2 & 600 & 21 \\
\hline $4^{*}$ & 71 & M & 11 & & & 28 & 2 & Mild-mod & 4 & 1100 & 23 \\
\hline 5 & 76 & M & 12 & & & 32 & 2 & Mild-mod & 3 & 950 & 26 \\
\hline $6^{*}$ & 54 & M & 23 & & & 31 & 2 & Mild-mod & 2 & 1800 & 29 \\
\hline $7^{*}$ & 74 & M & 8 & & & 40 & 2 & Mild-mod & 3 & 1050 & 24 \\
\hline 8 & 52 & M & 6 & 2 & Yes & 27 & 3 & Severe & 3 & 200 & 25 \\
\hline 9 & 67 & M & 15 & 2 & Yes & 16 & 3 & Severe & 3 & 1075 & 13 \\
\hline 10 & 69 & M & 12 & 5 & Yes & 27 & 3 & Severe & 3 & 0 & 20 \\
\hline 11 & 65 & M & 16 & 2 & No & 15 & 2 & Mild-mod & 3 & 1000 & 27 \\
\hline 12 & 65 & M & 21 & & & 29 & 3 & Severe & 2 & 1350 & 20 \\
\hline 13 & 58 & M & 11 & 1 & Yes & 17 & 2 & Mild-mod & 3 & 370 & 27 \\
\hline 14 & 80 & M & 3 & & & 22 & 3 & Severe & 3 & 400 & 11 \\
\hline $15^{*}$ & 64 & M & 12 & 5 & Yes & 27 & 2 & Mild-mod & 3 & 500 & 27 \\
\hline $16^{*}$ & 77 & $\mathrm{~F}$ & 15 & & & 31 & 3 & Severe & 3 & 700 & 15 \\
\hline M & 67.7 & & 13.7 & 3.7 & & 24.7 & 2.5 & & 2.8 & 799.7 & 21.6 \\
\hline
\end{tabular}

*PD participants who purchased the LR device for long-term use.

completed by the IWPD and their CPs at both visits. The three questions included (Q1) What is your typical speech loudness? (Q2) Overall, are you interested in using this device on a regular daily basis? (Q3) How satisfied are you with how effective the device is (the degree to which the device meets your needs)? The participant completed each question by placing a vertical line on a $10-\mathrm{cm}$ horizontal line with endpoints corresponding to the following: Q1 normal loudness versus very quiet, Q2 high interest versus low interest, Q3 very satisfied versus not satisfied. The first endpoint listed for each question reflects a higher rating score value (maximum $=10$ ).

A series of planned t-tests were used to examine speech intensity across the four conditions and two visits. A series of planned t-tests were also used to examine questionnaire scores across the two visits and across the two participant groups. These t-tests were corrected for multiple comparisons using the Bonferroni procedure. A 6-month follow-up visit was originally planned but none of the participants continued to use the device for more than 4 months. Follow-up telephone calls were done at 2 and 4 months to address participant concerns about device acceptance and performance.

\section{Results}

The average conversational speech intensity results for the four device conditions obtained during the first visit are shown in Figure 1. All six of the pairwise t-tests involving the four device conditions were significant $(\mathrm{p}<.001)$. Relative to the no-device condition $(\mathrm{M}=61.2 ; \mathrm{SD}=4.4 \mathrm{~dB})$, the speech intensity increased by $+10 \mathrm{~dB}$ during the bilateral $90 \mathrm{~dB}$ MTN condition
$(\mathrm{M}=71.2 ; \mathrm{SD}=3.4 \mathrm{~dB}),+7 \mathrm{~dB}$ during the bilateral $80 \mathrm{~dB} \mathrm{MTN}$ condition $(\mathrm{M}=68.2 ; \mathrm{SD}=3.2 \mathrm{~dB})$, and $+3.3 \mathrm{~dB}$ during the mono-lateral $80 \mathrm{~dB}$ MTN condition $(\mathrm{M}=64.5$; $\mathrm{SD}=3.7 \mathrm{~dB})$. For each of the four device conditions (i.e. no device, $80 \mathrm{~dB}$ bilateral MTN, etc.), the average speech intensity value obtained on the first visit was compared to the value obtained at the second 2-week visit. No significant difference was found any of these speech intensity comparisons across the first and second visits. Thus, the effects of the LR device conditions appear to have been maintained across the 2-week trial period. In addition, no significant difference in average speech intensity was found between the conversational and sentence-reading tasks. Figure 2 shows the conversational speech intensity obtained for each IWPD during the no-device and the bilateral $80 \mathrm{~dB}$ MTN device condition (note: this condition was used during the 2-week trial period). This figure illustrates the wide range of individual LRs (1-14 dB). The figure also indicates that the severity of hypophonia (i.e. the speech intensity in dB SPL obtained during the no-noise condition) does not appear to be a good predictor of the magnitude of the LR. A similar result has been found in a previous study of the LR in PD. ${ }^{5}$ For example, PD5 and PD11 have a milder hypophonia and they show a strong and weak LR, respectively. In contrast, PD2 and PD14 have a moderate-severe hypophonia and they also show a strong and weak LR, respectively.

The results for the first rating scale question obtained from the CPs are shown in Figure 3. These results relate to perceived speech loudness of the IWPDs when they are talking with and without the LR device. These ratings were obtained at the 2-week visit and they indicate that all of the CPs rated the respective IWPD as having a large increase in loudness when using the LR 


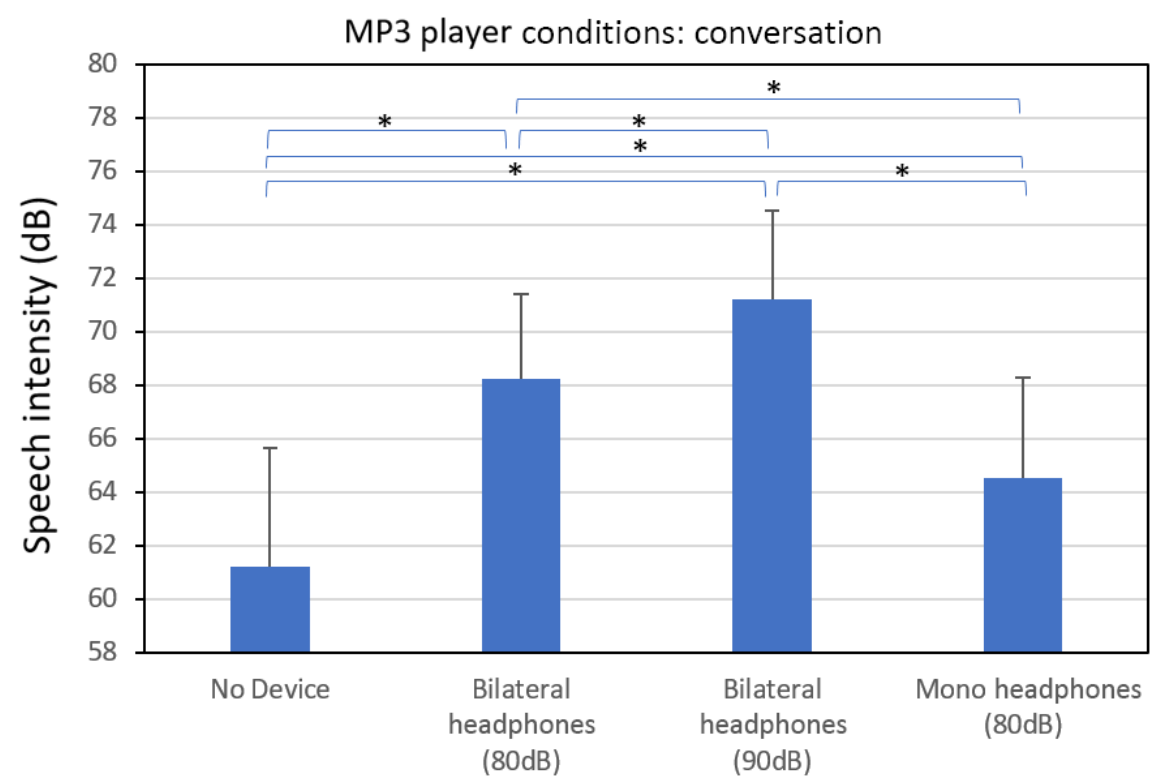

Figure 1: Average conversational speech intensity obtained from individuals with Parkinson's disease during the following Lombard-response device conditions: no-device, bilateral headphones playing $80 \mathrm{dBA}$ SPL of multi-talker noise, bilateral headphones playing $90 \mathrm{dBA} S \mathrm{SPL}$ of multi-talker noise, and mono-lateral headphones playing $80 \mathrm{dBA}$ SPL of multi-talker noise. A significant difference $(p<.05)$ between device conditions is indicated by the $\left({ }^{*}\right)$ symbol.

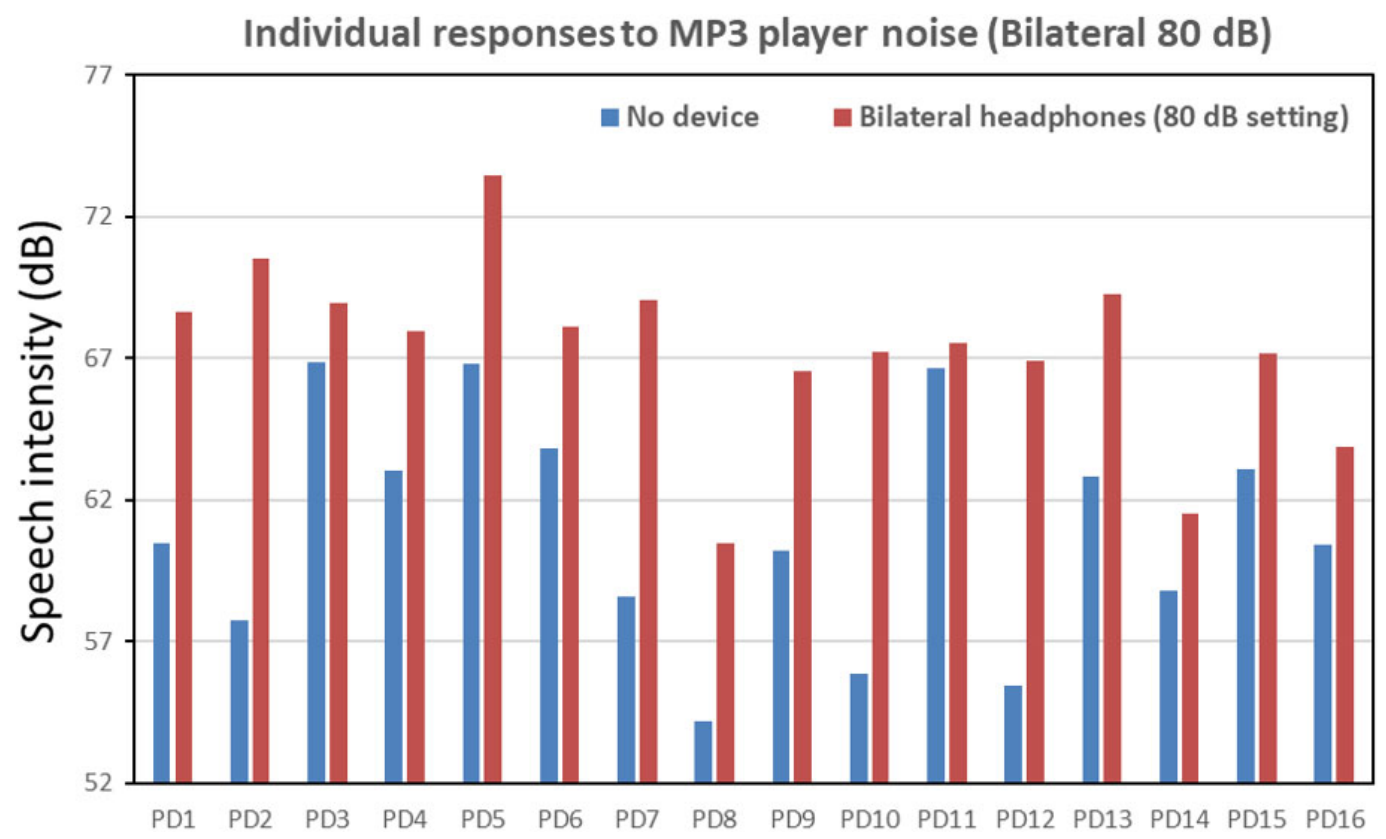

Figure 2: Average conversational speech intensity (dBA SPL) obtained for each of the 16 IWPD during the no-device and the bilateral $80 \mathrm{~dB}$ MTN device condition (this condition was used during the 2-week trial period).

device. The average $\mathrm{CP}$ rating of perceived loudness with the device $(\mathrm{M}=7.4 ; \mathrm{SD}=1.2)$ was significantly higher $(\mathrm{p}<.001)$ than without the device $(\mathrm{M}=1.7 ; \mathrm{SD}=1.4)$.

To evaluate the CP loudness ratings, obtained at the 2-week visit, in more detail, we examined the association between the change in the $\mathrm{CP}$ ratings of loudness and the previously presented change in the speech intensity measures using a correlation procedure. This correlation involved the $\mathrm{CP}$ reported change in loudness with the device (i.e. difference in $\mathrm{CP}$ ratings of perceived loudness between no-device and device-use conditions) and the quantitative change in speech intensity (i.e. difference in speech intensity between the no-device and the 80-dB bilateral device condition). This correlation was not significant $(\mathrm{r}=.038$ and $\mathrm{p}=.89)$ and suggests that the brief lab-based evaluation of the effect of a LR device on speech intensity may not be a good predictor CP ratings of the effectiveness of a LR device following a longer 2-week trial conducted outside of the lab. 


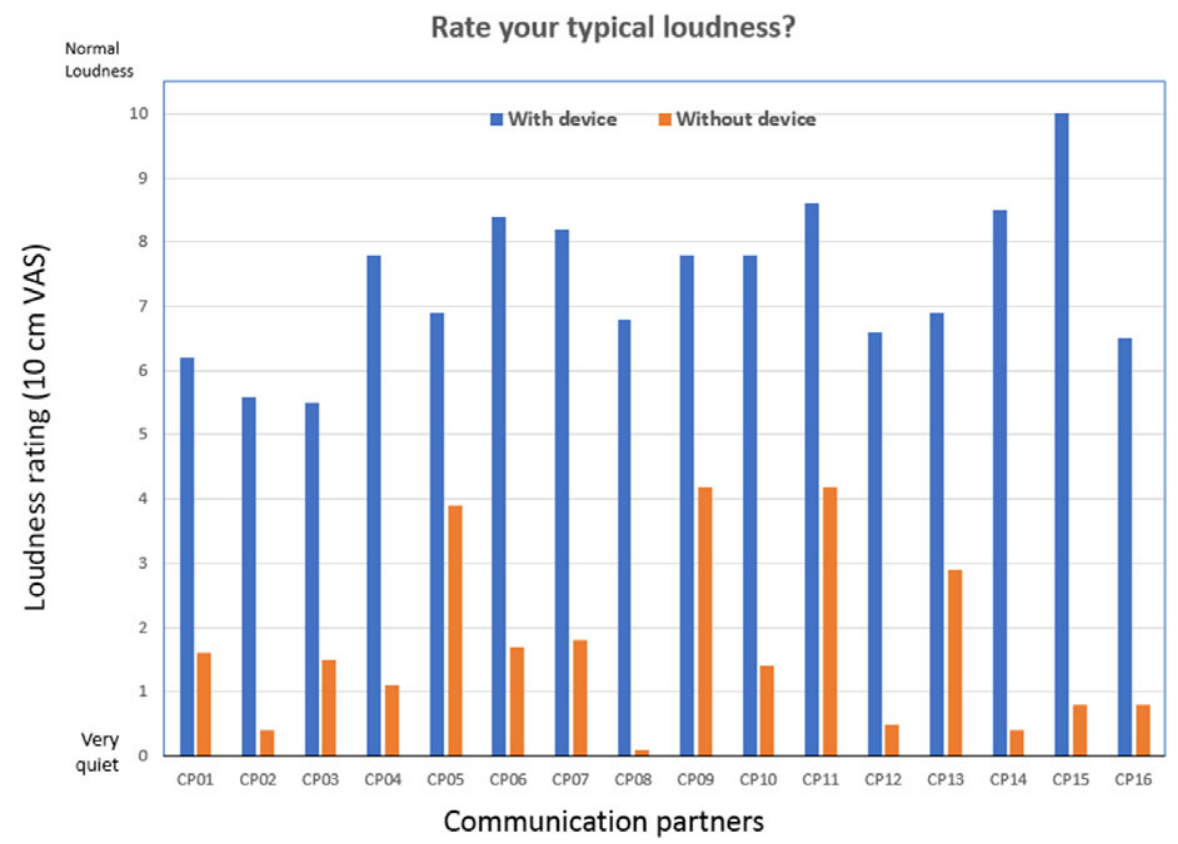

Figure 3: Loudness ratings with and without the Lombard-response device. Communication partners speech loudness ratings (question 1) of the individuals with Parkinson's disease when talking with and without the Lombard-response device. These ratings are presented for each of the 16 communication partners. These ratings were obtained after the 2-week device trial period.

The results for the second question related to rating the level of interest in continuing to use the device is shown in Figure 4. This figure shows the individual CP and IWPD ratings related to the level of interest in continuing to use the LR device following the 2-week trial period. The $\mathrm{CP}$ ratings were slightly higher than the IWPD ratings $(\mathrm{p}=.07)$. Eight of the $16 \mathrm{CPs}$ gave fairly high level of interest ratings. Each of these eight CP/IWPD pairs decided to purchase the LR device and to continue using it on a daily basis (see * in Figure 4).

The results for the third question related to the satisfaction with the effectiveness of the device are shown in Figure 5. This figure shows the individual CP and IWPD ratings related to satisfaction with the effectiveness of the device following the 2 -week trial period. The $\mathrm{CP}$ ratings were not significantly different from the IWPD ratings $(p=.29)$. In general, the CPs who gave high device effectiveness ratings were part of the eight CP/IWPD pairs that decided to purchase the LR device and to continue using it on a daily basis. Eight of the IWPD/CPs decided to purchase the LR device for long-term use. The other eight IWPD/CPs decided not to continue using the device because they found it too loud (uncomfortable or irritating), gave them a headache, interfered with their thinking, or was too difficult to control.

For the eight IWPD/CPs who purchased the LR device, none of the individuals reported that they were still using the device at the 4-month follow-up phone call. The reasons for discontinuing the device were the same as previously mentioned for the other eight IWPD/CPs. Five of the eight IWPD/CPs who purchased the LR device indicated that they might be interested in trying another low-cost LR device with a voice activation feature if it were developed in the future.

\section{Discussion}

In general, the LR device was found to provide immediate and short-term benefit to hypophonia in a group of IWPD. An immediate LR has been demonstrated in several previous studies of IWPD and hypophonia. ${ }^{5-8}$ The results of the present study indicate that the LR remained constant at a 2-week retest interval. The daily use of the LR device ( +2 hours/day) did not appear to reduce the magnitude of the LR over this 2-week interval. Previous studies have shown a similar continuation of the LR following 8 weeks of regular use of a LR device. ${ }^{11,12}$ It appears that the LR in IWPD is resistant to habituation or adaptation following regular daily use of a LR device. The magnitude of the average LR that was observed in the IWPD in the present study $(+7 \mathrm{~dB})$ is slightly higher than the average magnitude $(2-5 \mathrm{~dB})$ that has been reported in previous studies. ${ }^{5-8,11}$ These cross-study differences in the LR magnitude are probably related to differences in noise levels, noise types, speech tasks, and noise presentation methods. These inconsistencies indicate the need to develop standard procedures for the evaluation and comparison of LR devices in the future.

The present study provided new information related to the effects of mono-lateral versus bilateral noise presentation on the LR in IWPD. The mono-lateral condition was associated with approximately a 50\% reduction in the LR relative to the bilateral condition. This result indicates that mono-lateral versus bilateral presentation methods need to be given consideration in future LR device performance evaluations. It should be noted that in the present study, following the 2-week trial period, some of the participants were told that they could experiment with monolateral use of the LR device at times when they were finding it difficult to hear the other talkers or when they were having 

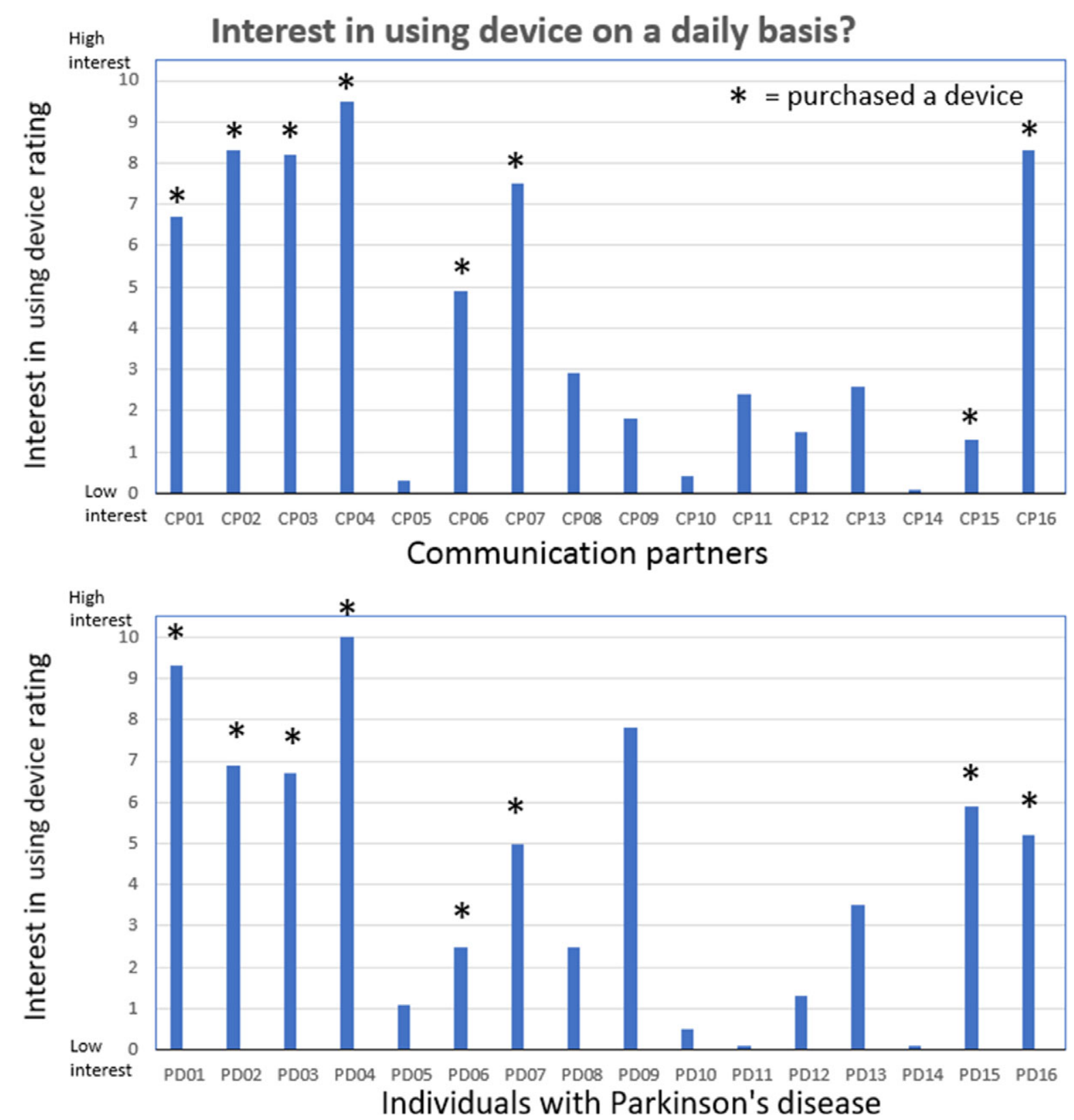

Figure 4: Interest in continuing to use the device ratings. Communication partner (upper pane) and individuals with Parkinson's disease (lower pane) rating scores related to the level of interest in continuing to use the LR device (question 2) following the 2-week trial period. Eight of the CP/IWPD pairs decided to purchase the LR device and to continue using it on a daily basis (shown by *).

difficulty switching the device on and off. This mono-lateral suggestion was not given to participants who had demonstrated a poor LR in the mono-lateral condition. In general, the bilateral presentation was recommended as the primary and preferred method of using the LR device throughout this study.

Previous studies of the LR or LR devices in IWPD have rarely examined listener perception of changes in loudness. ${ }^{14}$ The present study provides important information about the effects of a LR device on the perception of loudness from the novel perspective of the CP. The CPs showed a fourfold increase in their average speech loudness rating scores when the LR device was used to alter the speech of their partners with PD. CP ratings of loudness appear to be a useful procedure in the evaluation of
LR devices. These procedures may prove to be sensitive measures in future device comparison studies. Similarly, the ratings of device satisfaction, effectiveness, and experiences by the CPs and the IWPD provide potentially useful procedures and sensitive measures for evaluating differences between LR devices. In the present study, the higher rating scores on the device experience and satisfaction questions appeared to be closely associated with the participant's decision to purchase the LR device for long-term use.

The results of the present study indicate the importance of LR device trial periods in the process of evaluating device efficacy and acceptance. In this study, all 16 IWPD and their CPs were willing to evaluate the LR device for a 2 -week trial period after their initial 1-hour experience with the device. However, 

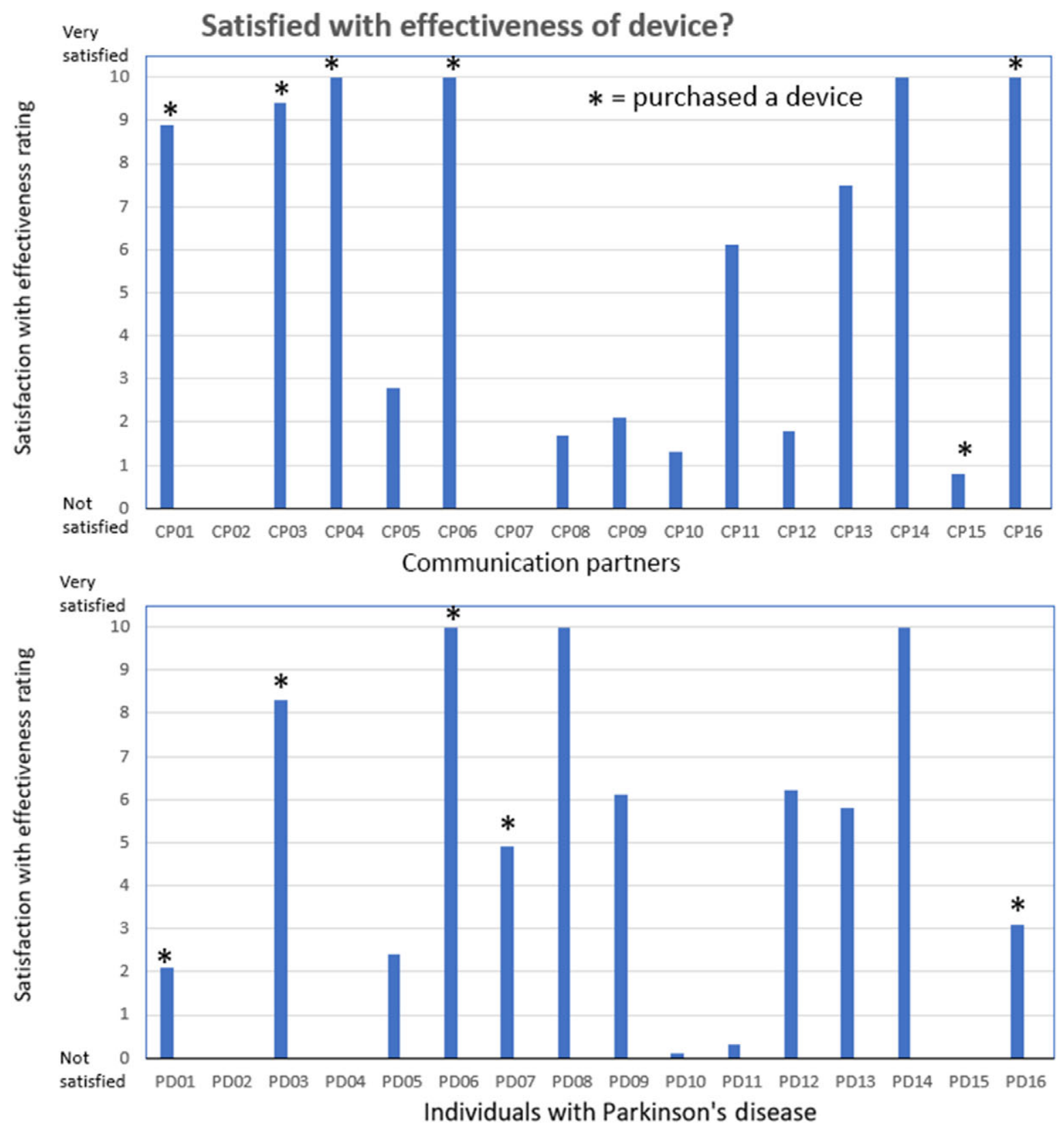

Figure 5: Satisfication with device effectiveness ratings. Communication partner (upper pane) and individuals with Parkinson's disease (lower pane) rating scores related to the level satisfaction with the effectiveness of the device (question 3) following the 2-week trial period. Eight of the CP/IWPD pairs decided to purchase the LR device and to continue using it on a daily basis (shown by*).

following this 2-week trial period, only half (8/16) of the participants were interested in continuing to use and purchased their own LR device. In contrast, after an additional 4 months of device use, none of the eight participants were continuing to use their purchased device. These device acceptance and abandonment results at different time points indicate that future studies of LR devices may need to consider extending the device trial periods to at least 4 months in order to evaluate the long-term acceptance of an LR device. Similar device trial periods may need to be considered in other types of communication devices for IWPD (i.e. voice amplifiers).

A limitation of the present study was the interview procedure that was used to evaluate the device rejection or abandonment.
This procedure consisted of open-ended questions about the participant's reasons for device rejection following the 2-week trial or the reasons for device abandonment at the 4-month period following the device purchase. The results of these interviews indicated the potential importance of factors such as discomfort and irritation with the noise level, associated headaches, interference with thinking, and difficulties with device controls, but these factors were not carefully evaluated. Further work is required to develop more systematic evaluations via questionnaires, rating scales, and qualitative interview-based procedures to gain better insight into the cause of device rejection. It should be noted that a challenge for these types of subjective measures is the risk of performance bias. Ideally, the risk of performance bias 
would be addressed using blinding procedures. Unfortunately, it is difficult to incorporate blinding into studies involving patient self-ratings and CP ratings of speech device performance and effectiveness. A potential solution is to include an objective outcome measure such as a wearable recording device that could provide long-term physical measures of the effects of a LR device on speech intensity in everyday social contexts.

Another limitation of the present study is that most of the PD participants were male (14/16). This sex bias limits the ability to generalize the results of the study to female IWPDs. It should be noted that both female participants were among the IWPD who decided to obtain a LR device for long-term use. Similar to the six male participants who obtained a LR device, the two female participants also abandoned the device by the 4-month follow-up.

A consideration that was not addressed in the present study is the potential adverse effects of wearing a LR device while walking and talking. While none of the participants in the present study reported negative effects of the LR device on their gait or balance, this potential effect requires systematic evaluation in future studies.

A final limitation of the present study is the absence of information about the effect of the LR device on speech intelligibility. Although the speech loudness and speech intensity are considered the primary outcome measures in treatment studies of hypophonia, the effect on speech intelligibility is an important secondary outcome measure. In the present study, it is assumed that an increase in speech intensity would have the effect of improving speech intelligibility in the context of everyday conditions involving talking in background noise, but the effect of the LR device on speech intelligibility was not systematically examined in the present study.

The low-cost LR device used in this study was found to provide immediate and short-term benefit to hypophonia in a group of IWPD and their CPs. Unfortunately, the long-term acceptance and use of the LR device were very poor. Future studies are required to determine if a new LR device can be developed with features that improve long-term efficacy and acceptance in IWPD and hypophonia.

\section{ACKNOWLEDGMENTS}

The authors would like to thank Eisha Gupta, Samantha Symonds, and Jeanninne Holt-Ulacia for their assistance with acoustic measures of speech intensity.

\section{Disclosures}

SA received salary support from Western University and received research grants from Parkinson Canada, Parkinson Society of Southwestern Ontario, and Merz Pharma.

AS was a graduate student at Western University and received a graduate student award from Parkinson Canada.

TK was a graduate student at Western University and received a graduate student award from the Parkinson Society of Southwestern Ontario.

MJ has received grants from CIHR, MITACS, OCE, Merz, Allergan, Abbvie, and Boston Scientific. MJ has also received speaker fees from Merz, Allergan, Abbvie, and UCB Pharma.

$\mathrm{NK}, \mathrm{PR}, \mathrm{AH}, \mathrm{JZ}$, and CM have nothing to disclose.

\section{STATEMENT OF AUTHORSHIP}

SA designed and conceptualized study; analyzed and interpreted data and wrote the first draft of the manuscript.

NK designed and conceptualized study; involved in participate recruitment, collected clinical data, interpreted data; and reviewed manuscript.

PR designed and conceptualized study; involved in participate recruitment, collected clinical data, interpreted data; and reviewed manuscript.

AH assisted with design of study, scheduling of participants, and data collection.

JZ assisted with scheduling of participants and data collection.

AS assisted with data collection, data analysis, and manuscript revisions.

$\mathrm{CM}$ assisted with data collection, data analysis and manuscript revisions.

TK assisted with data collection, data analysis, and manuscript revisions.

MJ involved in design of study and manuscript revisions.

\section{REFERENCES}

1. Adams SG, Jog M. Parkinson's disease. In: McNeil MR, editor. Clinical management of sensorimotor speech disorders. New York: Thieme; 2009, pp. 365-368.

2. Wirdefeldt K, Adami, H, Cole P, et al. Epidemiology and etiology of Parkinson's disease: a review of the evidence. Eur J Epidemiol. 2011;26(Suppl. 1):S1-58.

3. Atkinson-Clement C, Sadat J, Pinto, S. Behavioral treatments for speech in Parkinson's disease: meta-analyses and review of the literature. Neurodegener Dis Manag. 2015;5(3):233-248.

4. Adams SG, Dykstra A. Hypokinetic dysarthria. In: McNeil MR, editor. Clinical management of sensorimotor speech disorders. New York: Thieme; 2009, pp. 166-186.

5. Adams SG, Lang AE. Can the Lombard effect be used to improve low voice intensity in Parkinson's disease? Int J Lang Commun Disord. 1992;27(2):121-7.

6. Adams SG, Dykstra A, Abrams K, et al. Conversational speech intensity under different noise conditions in hypophonia and Parkinson's disease. Can Acoust. 2006;34(3):96-97.

7. Adams SG, Moon B, Dykstra A, et al. Effects of multi-talker noise on conversational speech in Parkinson's disease. J Med Speech Lang Pathol. 2006;14(4):221-228.

8. Ho AK, Bradshaw JL, Iansek R, et al. Speech volume regulation in Parkinson's disease: effects of implicit cues and explicit instructions. Neuropsychologia. 1999;37(13):1453-1460.

9. Lane H, Tranel B. The Lombard sign and the role of hearing in speech. J Speech Hear Res. 1971;14:677-709.

10. Brumm H, Zollinger SA. The evolution of the Lombard effect: 100 years of psychoacoustic research. Behaviour. 2011;148:1173-1198.

11. Stathopoulos ET, Huber JE, Richardson K, et al. Increased vocal intensity due to the Lombard effect in speakers with Parkinson's disease: simultaneous laryngeal and respiratory strategies. J Commun Disord. 2014;48(1):1-17.

12. Richardson K, Sussman JE, Stathopoulos ET, et al. The effect of increased vocal intensity on interarticulator timing in speakers with Parkinson's disease: a preliminary analysis. J Commun Disord. 2014;52(1):44-64.

13. Boersma P, Weenink D. Praat: doing phonetics by computer, Version 6.0.22. 2017. Available at: http://www.praat.org/; accessed January 28, 2017.

14. Heracleous P, Even J, Ishi C, et al. The role of the Lombard reflex in Parkinson's disease. In: IEEE 12th international conference on BioInformatics and BioEngineering, BIBE 2012. Red Hook, NY: Curran Associates, 2012, pp. 392-395. 